\title{
Determinants of bone mineral density in obese premenopausal
}

\section{women}

Miriam A. Bredella ${ }^{\mathrm{a}}$, Martin Torriani ${ }^{\mathrm{a}}$, Reza Hosseini Ghomia ${ }^{\mathrm{a}}$, Bijoy J. Thomas ${ }^{\mathrm{a}}$, Danielle J. Brick $^{\mathrm{b}}$, Anu V. Gerweck ${ }^{\mathrm{b}}$, Lindsey M. Harrington ${ }^{\mathrm{b}}$, Anne Breggia ${ }^{\mathrm{c}}$, Clifford J. Rosen ${ }^{\mathrm{c}}$, and Karen K. Millerb

a Department of Radiology, Massachusetts General Hospital and Harvard Medical School, Yawkey 6E, 55 Fruit Street, Boston, MA 02114

b Neuroendocrine Unit, Massachusetts General Hospital and Harvard Medical School, Bulfinch 457B, 55 Fruit Street, Boston, MA

${ }^{c}$ Maine Medical Center Research Institute, Scarborough, Maine 04074

\section{Abstract}

Despite being a risk factor for cardiovascular disease and diabetes mellitus, obesity has been thought to protect against osteoporosis. However, recent studies have demonstrated a differential impact of specific fat compartments on bone mineral density (BMD) with visceral adipose tissue (VAT) having potential detrimental effects on BMD. Visceral obesity is also associated with dysregulation of the GH/IGF-1 axis, an important regulator of bone homeostasis. The purpose of our study was to evaluate the differential effects of abdominal fat depots and muscle, vitamin D, and hormonal determinants, including insulin-like growth factor-1 (IGF-1), testosterone, and estradiol, on trabecular BMD of the lumbar spine. We studied 68 healthy obese premenopausal women (mean BMI: $36.7 \pm 4.2 \mathrm{~kg} / \mathrm{m}^{2}$ ). Quantitative computed tomography (QCT) was used to assess body composition and lumbar trabecular BMD. There was an inverse association between BMD and VAT, independent of age and BMI ( $\mathrm{p}=0.003)$. IGF-1 correlated positively with BMD and negatively with VAT and, in stepwise multivariate regression modeling, was the strongest predictor of BMD and procollagen type 1 amino-terminal propeptide (P1NP). Thigh muscle cross sectional area (CSA), and thigh muscle density were also associated with $\mathrm{BMD}(\mathrm{p}<0.05)$, but 25hydroxyvitamin $\mathrm{D}[25(\mathrm{OH}) \mathrm{D}]$, testosterone, free testosterone and estradiol levels were not. 25(OH)D was associated inversely with BMI, total and subcutaneous abdominal adipose tissue $(\mathrm{p}<0.05)$. These findings support the hypothesis that VAT exerts detrimental effects, whereas muscle mass exerts positive effects on BMD in premenopausal obese women. Moreover, our findings suggest that IGF-1 may be a mediator of the deleterious effects of VAT on bone health through effects on bone formation.

Corresponding author: Miriam A. Bredella, MD, Massachusetts General Hospital, Yawkey 6E, 55 Fruit Street, Boston, MA 02114, Phone: 617-726-7717, Fax: 617-726-5282, mbredella@partners.org.

\section{Disclosures}

The authors have no conflict of interest to declare.

Publisher's Disclaimer: This is a PDF file of an unedited manuscript that has been accepted for publication. As a service to our customers we are providing this early version of the manuscript. The manuscript will undergo copyediting, typesetting, and review of the resulting proof before it is published in its final citable form. Please note that during the production process errors may be discovered which could affect the content, and all legal disclaimers that apply to the journal pertain. 


\section{Keywords}

bone mineral density; obesity; visceral adipose tissue; IGF -1; P1NP; quantitative computed tomography (QCT)

\section{Introduction}

Obesity is a risk factor for cardiovascular and metabolic disease. However, it has been thought that obesity protects against bone loss via mechanical loading and effects of hormones secreted or regulated by adipocytes (1-3). Recent studies have suggested an inverse association between visceral adipose tissue (VAT) and bone mineral density (BMD) (4-6), whereas another study has demonstrated a potential protective effect of VAT on vertebral fractures in patients with diabetes mellitus(7). Several studies have suggested that lean mass is the strongest predictor of BMD in premenopausal women (8-10), stronger than estrogen, testosterone or progesterone (9). Therefore, further studies are needed to determine the effects of body composition on bone mineral density in obese $\mathrm{w}$ omen and to investigate potential mechanisms of these effects.

The growth hormone (GH)/insulin-like growth factor-1 (IGF-1) axis is a major determinant of BMD (11-14) and is dysregulated in women in proportion to their degree of visceral adiposity $(15,16)$. In addition, obese women have been found to have lower rates of bone formation, as measured by type I collagen, suggesting that increased body fat suppresses new collagen formation (17). W e studied the association between BMD and IGF-1 and procollagen type 1 amino-terminal propeptide (P1NP) in obese premenopausal women to investigate the hypothesis that IGF-1 may be a mediator of effects of VAT on bone formation and bone density.

The purpose of our study was to investigate hormonal and body composition determinants of BMD in healthy obese premenopausal women. Our goal was to evaluate the effects of different abdominal fat depots, thigh muscle area and density, using quantitative computed tomography (QCT), and hormonal determinants, such as IGF-1, P1NP, 25-hydroxyvitamin $\mathrm{D}[25(\mathrm{OH}) \mathrm{D}]$, testosterone, and estradiol, on trabecular BMD of the lumbar spine using QCT. We specifically hypothesized that higher degrees of VAT would be associated with lower bone density in association with lower P1NP and IGF-1 levels in obese women. Furthermore, we hypothesized that thigh muscle mass and quality would be positively associated with BMD andP1NP in this population.

\section{Materials and Methods}

The study was approved by Partners Healthcare Institutional Review Board and complied with Health Insurance Portability and Accountability Act guidelines. Written informed consent was obtained from all subjects after the nature of the procedures had been fully explained.

\subsection{Subjects}

The study group was comprised of 68healthy obese premenopausal women who were recruited from the community through advertisements. Inclusion criteria were female gender, ages 18 to 45 years, BMI $\geq 30 \mathrm{~kg} / \mathrm{m}^{2}$, and eumenorrhea. Exclusion criteria included hypothalamic or pituitary disorders, diabetes mellitus or other chronic illnesses, estrogen or glucocorticoid use. Each participant underwent quantitative computed tomography (QCT) for assessment of body composition and bone mineral density (BMD) as detailed below and 
fasting blood tests. Body composition, BMD, and clinical characteristics have been previously reported in 54 of the 68 subjects (18-21).

\subsection{Endocrine testing}

Subjects underwent the following fasting blood tests: insulin-like growth factor-1 (IGF-1), procollagen type 1 amino-terminal propeptide (P1NP) $(\mathrm{ng} / \mathrm{ml}), 25(\mathrm{OH}) \mathrm{D}(\mathrm{ng} / \mathrm{ml})$, sex hormone-binding globulin (SHBG) $(\mathrm{nmol} / \mathrm{l})$, free and total testosterone $(\mathrm{ng} / \mathrm{dl})$, free and total estradiol (pg/ml).

IGF-1, 25(OH)D, and P1NP were measured by IDS-iSYS Multi-Discipline Auomated Analyser based on chemiluminescence technology (Immunodiagnostic Systems, Inc., Fountain Hills, AZ). Minimum detection limits are: IGF-1 $4.4 \mathrm{ng} / \mathrm{ml}, 25(\mathrm{OH}) \mathrm{D} 3.6 \mathrm{ng} / \mathrm{ml}$, and P1NP $<1.0 \mathrm{ng} / \mathrm{ml}$. Within-run coefficients of variation (cv) are: IGF-1 1.4 to $2.0 \%$, 25(OH)D 5.5 to $12.1 \%$, and P1NP 2.6 to $3.0 \%$. Serum testosterone was measured by a Coata-Count analogue RIA kit (Siemens Healthcare Diagnostics Inc., Deerfield, IL) with an interassay cv of 5.9 to $12 \%$ and an analytical sensitivity of $4 \mathrm{ng} / \mathrm{dl}$.

SHBG was measured using a chemiluminescent microparticle Immunoassay kit from Architect (Abbot Laboratories, Abbot Park, IL) with a within-run cv of 4.78-5.24\% and an analytical sensitivity $\leq 0.1 \mathrm{nmol} / \mathrm{l}$. Free testosterone was calculated from total testosterone and SHBG by the laws of mass action, which has been validated in comparison to free testosterone by equilibrium dialysis in women (22).

Estradiol levels were measured using a chemiluminescent microparticle immunoassay kit from Architect (Abbot Laboratories, Abbot Park, IL), with a within -run CV of 1.5-6.4\% for concentrations of $45-192 \mathrm{pg} / \mathrm{ml}$ and a functional sensitivity $\leq 14 \mathrm{pg} / \mathrm{ml}$.

\subsection{Computed Tomography (CT) - Bone Mineral Density}

Trabecular bone mineral density (BMD) assessment of the fourth lumbar vertebral body (L4) was performed using quantitative computed tomography (QCT) on a LightSpeed CT scanner (General Electric, Milwaukee, WI). Scan parameters were: $144 \mathrm{~cm}$ table height, 80 $\mathrm{kV}, 70 \mathrm{~mA}$, scan time 2 seconds, $1 \mathrm{~cm}$ slice thickness, $48 \mathrm{~cm}$ field of view (FOV).

Patients were lying supine on a Mindways CT calibration phantom (Mindways, Austin, TX, USA) containing serial solutions of dipotassium hydrogen phosphate $\left(\mathrm{K}_{2} \mathrm{HPO}_{4}\right)$. Images were analyzed off-line on an Impax workstation (AGFA Diagnostic Software, version 4; Agfa, Ridgefield Park, NJ). A region of interest within trabecular bone of each vertebral body was placed manually, avoiding cortical bone and posterior veins. The mean density of each vertebral body and the density of the calibration solutions were used to calculate the mineral equivalent BMD using the following formula: $\mathrm{mg} / \mathrm{ml}$ of sample $=(\mathrm{CT} \#$ of sample intercept of calibration line)/slope of calibration line.

\subsection{Computed Tomography (CT) - Body composition}

Each subject underwent cross-sectional CT of the abdomen at the level of L4and 41 subjects underwent additional cross-sectional CT of the left mid-thigh as previously described (18). In short, a single $1 \mathrm{~cm}$ axial image of the abdomen and mid left thigh was obtained. Scan parameters were standardized: $144 \mathrm{~cm}$ table height, $80 \mathrm{kV}$ (abdomen), $120 \mathrm{kV}$ (thigh), $70 \mathrm{~mA}$ (abdomen), $170 \mathrm{~mA}$ (thigh), scan time 2 seconds, $48 \mathrm{~cm}$ FOV. Subcutaneous adipose tissue (SAT), visceral adipose tissue (VAT), and total adipose tissue (TAT) area was calculated. In the left thigh, fat and muscle cross sectional areas (CSA), as a measure of fat and muscle mass, and mean attenuation coefficient, measured in Hounsfield Units (HU) of thigh muscle 
tissue, as a measure of fatty infiltration, were determined (23). Analyses were performed using Alice software (version 4.3.9 Parexel, Waltham, MA).

\subsection{Proton MR Spectroscopy (1H-MRS)}

In order to determine whether the positive correlation between IGF - 1 and BMD may be a reflection of decreased bone marrow fat, we used previously published data on bone marrow fat content in a subset of 27 women. Bone marrow fat content was quantified using $1 \mathrm{H}-\mathrm{MRS}$ as previously described (19).

\subsection{Statistical Analysis}

JMP Statistical Database Software (version 5.0.1; SAS Institute, Cary, NC) was used for statistical analyses. Non-parametric Spearman rank correlation coefficients are reported. Multivariate standard least squares regression modeling was performed to control for age, BMI, and bone marrow fat. Forward stepwise regression modeling was also performed to determine predictors of BMD and P1NP. $\mathrm{P} \leq 0.05$ was used to denote significance and $\mathrm{p}<$ 0.1 was used to denote a trend. Data are presented as mean $\pm \mathrm{SD}$.

\section{Results}

\subsection{Clinical characteristics of study subjects}

Subject characteristics are shown in Table 1 . The age of study participants ranged from 21 to 45 years, with a mean of $35.9 \pm 6.7$ years. Study participants ranged in BMI from 30.2 to $49.7 \mathrm{~kg} / \mathrm{m}^{2}$, with a mean BMI of $36.7 \pm 4.2 \mathrm{~kg} / \mathrm{m}^{2}$.

\subsection{Associations of bone mineral density with body composition and hormones}

Associations of BMD and P1NP with body composition and hormones are shown in Table 2. There was an inverse association between $\mathrm{L} 4$ trabecular BMD and age $(\mathrm{r}=-0.41, \mathrm{p}=$ 0.0006). There were inverse associations betweenL4 trabecular BMD and VAT ( $r=-0.42$, $\mathrm{p}=0.0005$ ) (Figure 1), which remained significant after controlling for age and BMI using standard least squares regression modeling $(\mathrm{p}=0.003)$. There was a trend toward an inverse association between L4 trabecular BMD and TAT $(r=-0.23, \mathrm{p}=0.06)$ while there were no significant associations between $\mathrm{L} 4$ trabecular BMD and abdominal SAT or BMI $(\mathrm{p}=0.1)$. There were positive correlations between L4 trabecular BMD and thigh muscle CSA( $\mathrm{r}=0$. $42, \mathrm{p}=0.007)$ (Figure 2), which remained significant after controlling for BMI $(\mathrm{p}=0.008)$.

Trabecular BMD of L4 correlated positively with IGF-1 ( $\mathrm{r}=0.48, \mathrm{p}=0.0001)$ (Figure 3$)$. As IGF-1 decreases with age and increasing BMI, we controlled for age and BMI using standard least squares regression modeling. After controlling for age and BMI, the association between L4 trabecular BMD and IGF-1 remained significant ( $\mathrm{p}=0.04)$. We previously demonstrated an inverse association between IGF-1 and bone marrow fat (19). In order to determine, whether the positive correlation between IGF -1 and BMD was a reflection of less bone marrow fat, we controlled for bone marrow fat in the27 subjects for whom these data were available using standard least squares modeling. After controlling for bone marrow fat, the correlation between IGF-1 and trabecular BMD remained significant $(\mathrm{p}=0.03)$.

Fourteen subjects were vitamin D deficient [25(OH)D $<20 \mathrm{ng} / \mathrm{ml}](24)$, and 21 subjects were vitamin $\mathrm{D}$ insufficient $[25(\mathrm{OH}) \mathrm{D}<30 \mathrm{ng} / \mathrm{ml}](24)$. There were no associations between $\mathrm{L} 4$ trabecular BMD and 25(OH)D ( $\mathrm{p}=0.7)$.

There were no significant associations between L4trabecular BMD and estradiol, testosterone or SHBG ( $\mathrm{p}=0.3$ to $\mathrm{p}=0.8$ ). 
In order to determine the strongest predictors of trabecular BMD, we performed forward stepwise regression modeling. When L4 trabecular BMD was entered as a dependent variable and VAT, IGF-1, P1NP, and thigh muscle CSA, as independent variables, IGF-1 was the only predictor of BMD and explained $24 \%$ of the variability of $\mathrm{BMD}\left(\mathrm{r}^{2}=0.24, \mathrm{p}=\right.$ $0.001)$.

\subsection{Associations of P1NP with bone mineral density and body composition}

There was a positive correlation between L4 trabecular density and P1NP $(r=0.25, p=0.05)$ (Figure 4). P1NP demonstrated an inverse association with age ( $\mathrm{r}=-0.38, \mathrm{p}=0.002)$, a positive correlation with SAT $(r=0.31, p=0.02)$ and a trend toward an inverse association with VAT $(r=-0.21, p=0.09)$, whereas no significant associations with BMI, TAT, and thigh SAT were found ( $\mathrm{p}=0.1$ to $\mathrm{p}=0.5$ ). P1NP correlated positively with thigh muscle CSA $(0.35, \mathrm{p}=0.03)$, thigh muscle density $(\mathrm{r}=0.31, \mathrm{p}=0.05)$, and IGF-1 $(\mathrm{r}=0.49, \mathrm{p}=0.0001)$ (Figure 5).

Forward stepwise regression analysis was performed to determine the strongest predictors of P1NP. When P1NP was entered as a dependent variable and IGF-1, and thigh muscle CSA, $\mathrm{BMD}$, and SAT as independent variables, IGF-1 was the only predictor of P1NP and explained $35 \%$ of the variability of $\mathrm{BMD}\left(\mathrm{r}^{2}=0.35, \mathrm{p}<0.0001\right)$.

\subsection{Associations of body composition with hormones}

There were inverse associations between $25(\mathrm{OH}) \mathrm{D}$ and BMI $(\mathrm{r}=-0.29, \mathrm{p}=0.02)$, TAT $(\mathrm{r}=$ $-0.27, \mathrm{p}=0.04)$, SAT $(\mathrm{r}=-0.25, \mathrm{p}=0.05)$ but not with VAT $(\mathrm{p}=0.1)$. There was no significant association between $25(\mathrm{OH}) \mathrm{D}$ and thigh muscle CSA $(\mathrm{p}=0.8)$ or thigh muscle density $(\mathrm{p}=0.1)$. There was a positive correlation between $25(\mathrm{OH}) \mathrm{D}$ and IGF-1 $(\mathrm{r}=0.24, \mathrm{p}=$ $0.06)$, while there was no association between $25(\mathrm{OH}) \mathrm{D}$ andP1NP $(\mathrm{p}=0.2)$.

There was an inverse association between IGF-1 and BMI $(r=0.21, \mathrm{p}=0.01)$, TAT $(\mathrm{r}=0.25$, $\mathrm{p}=0.01)$, and VAT $(\mathrm{r}=-0.35, \mathrm{p}=0.0002)$, while there were no significant associations with SAT and thigh fat ( $\mathrm{p}=0.9$ and $\mathrm{p}=0.7$, respectively). IGF- 1 correlated positively with thigh muscle CSA ( $\mathrm{r}=0.46, \mathrm{p}=0.0027)$ and muscle density $(\mathrm{r}=0.47, \mathrm{p}=0.003)$.

There were no significant associations between free testosterone, free estradiol, and SHBG with BMI, abdominal and thigh fat depots, thigh muscle CSA or thigh muscle density ( $\mathrm{p}=$ 0.1 to $\mathrm{p}=0.9)$.

\section{Discussion}

We demonstrate in premenopausal obese women a $\mathrm{n}$ inverse association between VAT and L4 trabecular BMD. Moreover, we show that IGF-1, P1NP, and thigh muscle are positive predictors of BMD. These findings support the hypothesis that VAT exerts detrimental effects, whereas the increase muscle mass seen in obesity exerts positive effects on BMD in premenopausal obese women. The GH/IGF-1 axis is dysregulated in obesity, with VAT being a strong inverse determinant of endogenous $\mathrm{GH}$ secretion. Our findings suggest that IGF-1 may be a mediator of the deleterious effects of VAT on bone health through effects on bone formation. Further studies are needed to investigate other potential mediators.

Despite being a risk factor for cardiovascular disease, hypertension, and diabetes mellitus, obesity has been thought to protect against osteoporosis and fat mass has been found to be a positive predictor of BMD in many studies $(1,3,25-27)$. However, recent studies have demonstrated a differential impact of specific fat compartments on BMD with VAT having potential detrimental effects on BMD $(6,28)$. Visceral obesity is also associated with dysregulation of the GH/IGF-1 axis, an important regulator of bone homeostasis $(12,29,30)$. 
In addition, obese women have been found to have lower rates of bone formation, as measured by type I collagen, suggesting that increased body fat suppresses new collagen formation (17). Vitamin D, a regulator of bone metabolism, is inversely associated with obesity and fat mass, and vitamin D deficiency is emerging as a risk factor for the metabolic syndrome (31). Therefore we evaluated the effect of different abdominal fat depots, bone turnover markers, and hormones on BMD in premenopausal obese women.

Studies in children and young adults of various BMI have shown an inverse association of VAT with BMD $(6,28)$ and a positive correlation of SAT with BMD $(6)$. Other studies using DXA to determine body composition have found inverse associations of total body fat with $\operatorname{BMD}(5,32,33)$ and cortical CSA $(5,34)$. Potential explanations raised for these findings include the release of proinflammatory cytokines secreted by adipocytes, such as IL-6, TNF$\alpha$, and adipokines, such as E-selectin and adiponectin, stimulating osteoclast activity $(6,35-$ 37). Our data suggest that IGF-1 may be an important mediator of the effect s of VAT on the skeleton. VAT is a strong inverse determinant of endogenous GH secretion in women of reproductive age with obesity, and IGF-1 is also decreased in such women $(15,16)$. Our data demonstrate that IGF-1 correlates positively with BMD, independent of age and BMI. IGF-1 also correlated positively with P1NP suggesting that IGF-1 increases collagen synthesis which is important to maintain appropriate levels of bone matrix. These findings are concordant with prior studies showing a strong positive correlation between IGF-1 and BMD (11-14) and between IGF-1 and P1NP $(11,14)$. GH and IGF-1 are key regulators of bone homeostasis and fat mass, with increased visceral fat being associated with decreased GH/IGF-1 levels $(12,15)$. IGF-1 regulates osteoblast activity by decreasing collagen degradation and increasing osteoblast recruitment (12), and circulating IGF-1 is necessary for bone growth (38). We have previously demonstrated an inverse association between vertebral bone marrow fat and IGF-1 in premenopausal women ranging from normal weight to obese, supporting the role of IGF-1 as an important regulator of the fat and bone lineage (19). A limitation of the use of single-energy QCT for the assessment of BMD is the potential influence of marrow fat on BMD measurements. We therefore used data on vertebral bone marrow fat of 27 women. After controlling for bone marrow fat, the association between IGF-1 and BMD remained significant. This suggests that our results are not an artifact of our measurement technique. Our data from the current study therefore support a role for IGF-1 in the mediation of the negative effects of VAT on bone density.

Our data also suggest that muscle mass and quality play important roles in the maintenance of skeletal health in obese premenopausal women. Previously published data using DXA have suggested that lean body mass is an important determinant of bone density in premenopausal women. Lu et al (9) found that lean body mass, determined by DXA, was the strongest predictor of BMD of the spine and hip, whereas fat mass correlated positively with BMD of the hip in premenopausal women over a wide range of BMIs. Similarly, Wang et al (10) reported positive correlations between both lean and fat mass, determined by DXA, and BMD in young women, with lean mass having a greater positive effect on BMD than fat mass. Our data are consistent with these previously published data and are the first to examine this relationship using QCT to measure muscle area and quality, the previous studies all using surrogate measurements for muscle mass ("fat-free" or "lean body" mass), which do not directly measure muscle. Our study is also the first to focus exclusively on obese premenopausal women.

25(OH)D correlated positively with BMI and TAT, consistent with previous studies showing an inverse association between vitamin D levels and increased fat mass (39-42). Half of our subjects had abnormal vitamin D levels, with 20\%being vitamin D deficient and $30 \%$ being vitamin $\mathrm{D}$ insufficient. We did not find a significant association between $25(\mathrm{OH}) \mathrm{D}$ and $\mathrm{BMD}$, consistent with previous reports in adolescents and young adults 
$(40,43)$. A possible explanation for these findings might be that the detrimental effects of vitamin D deficiency on bone may not yet be present in premenopausal women.

Alternatively, the effects of vitamin D levels on bone density in this population may not be strong enough to be detected in a small number of study subjects.

We failed to show a significant association between BMD and estradiol, SHBG, or testosterone. Some prior studies have shown associations between gonadal steroid levels and BMD in premenopausal women $(44,45)$ where others, in which luteal phase $(9)$ and follicular phase (46) serum estradiol and testosterone was measured, also failed to show significant correlations between BMD and gonadal steroids.

A limitation of our study is the cross-sectional study design, which limits our ability to prove causality. Second, our study was focused on obese premenopausal women, and our findings cannot be extrapolated to post-menopausal women or men. We also did not control sampling of estradiol and testosterone to the phase of the menstrual cycle. Strengths of our study were the large number of obese premenopausal women, detailed evaluation of body composition and trabecular bone using QCT, and inclusion of hormonal determinants such as IGF-1, P1NP, and 25(OH)D.

\section{Conclusion}

In conclusion, in obese premenopausal women, VAT is a negative, and thigh muscle CSA and density, IGF-1, P1NP are positive, predictors of trabecular BMD. Our study supports the hypothesis that VAT exerts detrimental, and muscle positive effects on BMD. Moreover, IGF-1 was the strongest predictor of BMD and P1NP and was inversely determined by VAT in this population, suggesting that the effects of VAT on BMD may be at least partially mediated by IGF-1. Further studies are needed to investigate this hypothesis and other potential mediators of the effects of VAT on BMD.

\section{Research Highlights}

- We study effects of abdominal fat depots, muscle, and hormones on BMD in young obese women

- VAT exerts detrimental and muscle exerts positive effects on BMD

- IGF-1 may be mediator of deleterious effects of VAT on BMD through effects on bone formation

\section{Acknowledgments}

This work was supported in part by National Institutes of Health Grants RO1 HL-077674, UL1 RR-025758, and K23 RR-23090

\section{References}

1. Albala C, Yanez M, Devoto E, Sostin C, Zeballos L, Santos JL. Obesity as a protective factor for postmenopausal osteoporosis. Int J Obes Relat Metab Disord. 1996; 20:1027-1032. [PubMed: 8923160]

2. Klein KO, Larmore KA, de Lancey E, Brown JM, Considine RV, Hassink SG. Effect of obesity on estradiol level, and its relationship to leptin, bone maturation, and bone mineral density in children. J Clin Endocrinol Metab. 1998; 83:3469-3475. [PubMed: 9768648] 
3. Reid IR, Plank LD, Evans MC. Fat mass is an important determinant of whole body bone density in premenopausal women but not in men. J Clin Endocrinol Metab. 1992; 75:779-782. [PubMed: 1517366]

4. Gilsanz V, Chalfant J, Mo AO, Lee DC, Dorey FJ, Mittelman SD. Reciprocal Relations of Subcutaneous and Visceral Fat to Bone Structure and Strength. J Clin Endocrinol Metab. 2009

5. Janicka A, Wren TA, Sanchez MM, et al. Fat mass is not beneficial to bone in adolescents and young adults. J Clin Endocrinol Metab. 2007; 92:143-147. [PubMed: 17047019]

6. Russell M, Mendes N, Miller KK, et al. Visceral fat is a negative predictor of bone density measures in obese adolescent girls. J Clin Endocrinol Metab. 2010; 95:1247-1255. [PubMed: 20080853]

7. Yamaguchi T, Kanazawa I, Yamamoto M, et al. Associations between components of the metabolic syndrome versus bone mineral density and vertebral fractures in patients with type 2 diabetes. Bone. 2009; 45:174-179. [PubMed: 19446053]

8. Lekamwasam S, Weerarathna T, Rodrigo M, Arachchi WK, Munidasa D. Association between bone mineral density, lean mass, and fat mass among healthy middle-aged premenopausal women: a cross-sectional study in southern Sri Lanka. J Bone Miner Metab. 2009; 27:83-88. [PubMed: 19082777]

9. Lu LJ, Nayeem F, Anderson KE, Grady JJ, Nagamani M. Lean body mass, not estrogen or progesterone, predicts peak bone mineral density in premenopausal women. J Nutr. 2009; 139:250256. [PubMed: 19106315]

10. Wang MC, Bachrach LK, Van Loan M, Hudes M, Flegal KM, Crawford PB. The relative contributions of lean tissue mass and fat mass to bone density in young women. Bone. 2005; 37:474-481. [PubMed: 16040285]

11. Adami S, Zivelonghi A, Braga V, et al. Insulin-like growth factor-1 is associated with bone formation markers, PTH and bone mineral density in healthy premenopausal women. Bone. 2010; 46:244-247. [PubMed: 19853071]

12. Giustina A, Mazziotti G, Canalis E. Growth hormone, insulin-like growth factors, and the skeleton. Endocr Rev. 2008; 29:535-559. [PubMed: 18436706]

13. Szulc P, Joly-Pharaboz MO, Marchand F, Delmas PD. Insulin-like growth factor I is a determinant of hip bone mineral density in men less than 60 years of age: MINOS study. Calcif Tissue Int. 2004; 74:322-329. [PubMed: 15255068]

14. Walsh JS, Henry YM, Fatayerji D, Eastell R. Hormonal determinants of bone turnover before and after attainment of peak bone mass. Clin Endocrinol (Oxf). 2004; 72:320-327. [PubMed: 19508592]

15. Pijl H, Langendonk JG, Burggraaf J, et al. Altered neuroregulation of GH secretion in viscerally obese premenopausal women. J Clin Endocrinol Metab. 2001; 86:5509-5515. [PubMed: 11701729]

16. Utz AL, Yamamoto A, Hemphill L, Miller KK. Growth hormone deficiency by growth hormone releasing hormone-arginine testing criteria predicts increased cardiovascular risk markers in normal young overweight and obese women. J Clin Endocrinol Metab. 2008; 93:2507-2514. [PubMed: 18445664]

17. Papakitsou EF, Margioris AN, Dretakis KE, et al. Body mass index (BMI) and parameters of bone formation and resorption in postmenopausal women. Maturitas. 2004; 47:185-193. [PubMed: 15036488]

18. Bredella MA, Ghomi RH, Thomas BJ, et al. Comparison of DXA and CT in the Assessment of Body Composition in Premenopausal Women With Obesity and Anorexia Nervosa. Obesity (Silver Spring). 2010; 18:2227-33. [PubMed: 20111013]

19. Bredella MA, Torriani M, Ghomi RH, et al. Vertebral Bone Marrow Fat Is Positively Associated With Visceral Fat and Inversely Associated With IGF-1 in Obese Women. Obesity (Silver Spring). 2010

20. Bredella MA, Torriani M, Thomas BJ, et al. Peak growth hormone-releasing hormone-argininestimulated growth hormone is inversely associated with intramyocellular and intrahepatic lipid content in premenopausal women with obesity. J Clin Endocrinol Metab. 2009; 94:3995-4002. [PubMed: 19602559] 
21. Bredella MA, Utz AL, Torriani M, Thomas B, Schoenfeld DA, Miller KK. Anthropometry, CT, and DXA as predictors of GH deficiency in premenopausal women: ROC curve analysis. J Appl Physiol. 2009; 106:418-422. [PubMed: 19095751]

22. Miller KK, Rosner W, Lee H, et al. Measurement of free testosterone in normal women and women with androgen deficiency: comparison of methods. J Clin Endocrinol Metab. 2004; 89:525-533. [PubMed: 14764757]

23. Goodpaster BH, Kelley DE, Thaete FL, He J, Ross R. Skeletal muscle attenuation determined by computed tomography is associated with skeletal muscle lipid content. J Appl Physiol. 2000; 89:104-110. [PubMed: 10904041]

24. Holick MF. Vitamin D deficiency. N Engl J Med. 2007; 357:266-281. [PubMed: 17634462]

25. Douchi T, Oki T, Nakamura S, Ijuin H, Yamamoto S, Nagata Y. The effect of body composition on bone density in pre-and postmenopausal women. Maturitas. 1997; 27:55-60. [PubMed: 9158078]

26. Khosla S, Atkinson EJ, Riggs BL, Melton LJ 3rd. Relationship between body composition and bone mass in women. J Bone Miner Res. 1996; 11:857-863. [PubMed: 8725184]

27. Reid IR, Ames R, Evans MC, et al. Determinants of total body and regional bone mineral density in normal postmenopausal women--a key role for fat mass. J Clin Endocrinol Metab. 1992; 75:4551. [PubMed: 1619030]

28. Afghani A, Goran MI. The interrelationships between abdominal adiposity, leptin and bone mineral content in overweight Latino children. Horm Res. 2009; 72:82-87. [PubMed: 19690425]

29. Miller KK, Biller BM, Lipman JG, Bradwin G, Rifai N, Klibanski A. Truncal adiposity, relative growth hormone deficiency, and cardiovascular risk. J Clin Endocrinol Metab. 2005; 90:768-774. [PubMed: 15572428]

30. Mukherjee A, Murray RD, Shalet SM. Impact of growth hormone status on body composition and the skeleton. Horm Res. 2004; 62 (Suppl 3):35-41. [PubMed: 15539797]

31. Martini LA, Wood RJ. Vitamin D status and the metabolic syndrome. Nutr Rev. 2006; 64:479486. [PubMed: 17131943]

32. Fu X, Ma X, Lu H, He W, Wang Z, Zhu S. Associations of fat mass and fat distribution with bone mineral density in pre-and postmenopausal Chinese women. Osteoporos Int.

33. Hsu YH, Venners SA, Terwedow HA, et al. Relation of body composition, fat mass, and serum lipids to osteoporotic fractures and bone mineral density in Chinese men and women. Am J Clin Nutr. 2006; 83:146-154. [PubMed: 16400063]

34. Pollock NK, Laing EM, Hamrick MW, Baile CA, Hall DB, Lewis RD. Bone and fat relationships in postadolescent black females: a pQCT study. Osteoporos Int. 2010

35. Cartier A, Lemieux I, Almeras N, Tremblay A, Bergeron J, Despres JP. Visceral obesity and plasma glucose-insulin homeostasis: contributions of interleukin-6 and tumor necrosis factor-alpha in men. J Clin Endocrinol Metab. 2008; 93:1931-1938. [PubMed: 18319319]

36. Pou KM, Massaro JM, Hoffmann U, et al. Visceral and subcutaneous adipose tissue volumes are cross-sectionally related to markers of inflammation and oxidative stress: the Framingham Heart Study. Circulation. 2007; 116:1234-1241. [PubMed: 17709633]

37. Wood IS, Wang B, Jenkins JR, Trayhurn P. The pro-inflammatory cytokine IL-18 is expressed in human adipose tissue and strongly upregulated by TNFalpha in human adipocytes. Biochem Biophys Res Commun. 2005; 337:422-429. [PubMed: 16188228]

38. Yakar S, Rosen CJ, Beamer WG, et al. Circulating levels of IGF -1 directly regulate bone growth and density. J Clin Invest. 2002; 110:771-781. [PubMed: 12235108]

39. Konradsen S, Ag H, Lindberg F, Hexeberg S, Jorde R. Serum 1,25-dihydroxy vitamin D is inversely associated with body mass index. Eur J Nutr. 2008; 47:87-91. [PubMed: 18320256]

40. Kremer R, Campbell PP, Reinhardt T, Gilsanz V. Vitamin D status and its relationship to body fat, final height, and peak bone mass in young women. J Clin Endocrinol Metab. 2009; 94:67-73. [PubMed: 18984659]

41. Parikh SJ, Edelman M, Uwaifo GI, et al. The relationship between obesity and serum 1,25dihydroxy vitamin D concentrations in healthy adults. J Clin Endocrinol Metab. 2004; 89:11961199. [PubMed: 15001609] 
42. Young KA, Engelman CD, Langefeld CD, et al. Association of plasma vitamin D levels with adiposity in Hispanic and African Americans. J Clin Endocrinol Metab. 2009; 94:3306-3313. [PubMed: 19549738]

43. Kristinsson JO, Valdimarsson O, Sigurdsson G, Franzson L, Olafsson I, Steingrimsdottir L. Serum 25-hydroxyvitamin D levels and bone mineral density in 16-20 years-old girls: lack of association. J Intern Med. 1998; 243:381-388. [PubMed: 9651561]

44. Slemenda C, Longcope C, Peacock M, Hui S, Johnston CC. Sex steroids, bone mass, and bone loss. A prospective study of pre-, peri-, and postmenopausal women. J Clin Invest. 1996; 97:1421. [PubMed: 8550826]

45. Steinberg KK, Freni-Titulaer LW, DePuey EG, et al. Sex steroids and bone density in premenopausal and perimenopausal women. J Clin Endocrinol Metab. 1989; 69:533-539. [PubMed: 2527242]

46. Sowers MR, Finkelstein JS, Ettinger B, et al. The association of endogenous hormone concentrations and bone mineral density measures in pre- and perimenopausal women of four ethnic groups: SWAN. Osteoporos Int. 2003; 14:44-52. [PubMed: 12577184] 


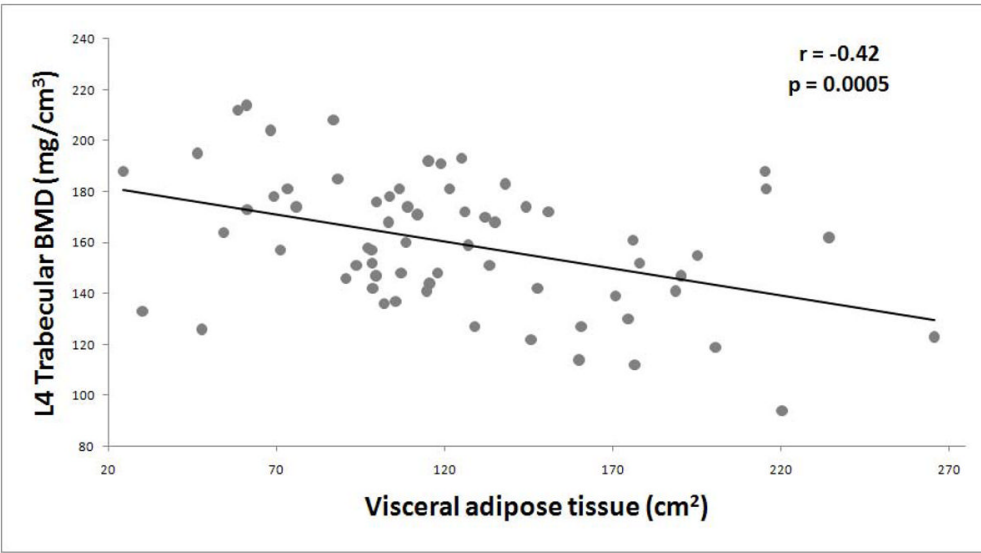

Figure 1.

Regression analysis of L4 trabecular BMD on visceral adipose tissue. There is an inverse association between bone mineral density and visceral adipose tissue. 


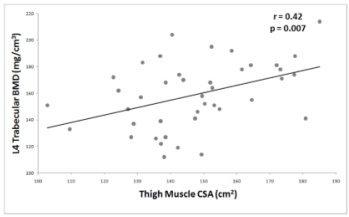

Figure 2.

Regression analysis of L4 trabecular BMD on thigh muscle cross sectional area. There is a positive correlation between bone mineral density and thigh muscle cross sectional area. 


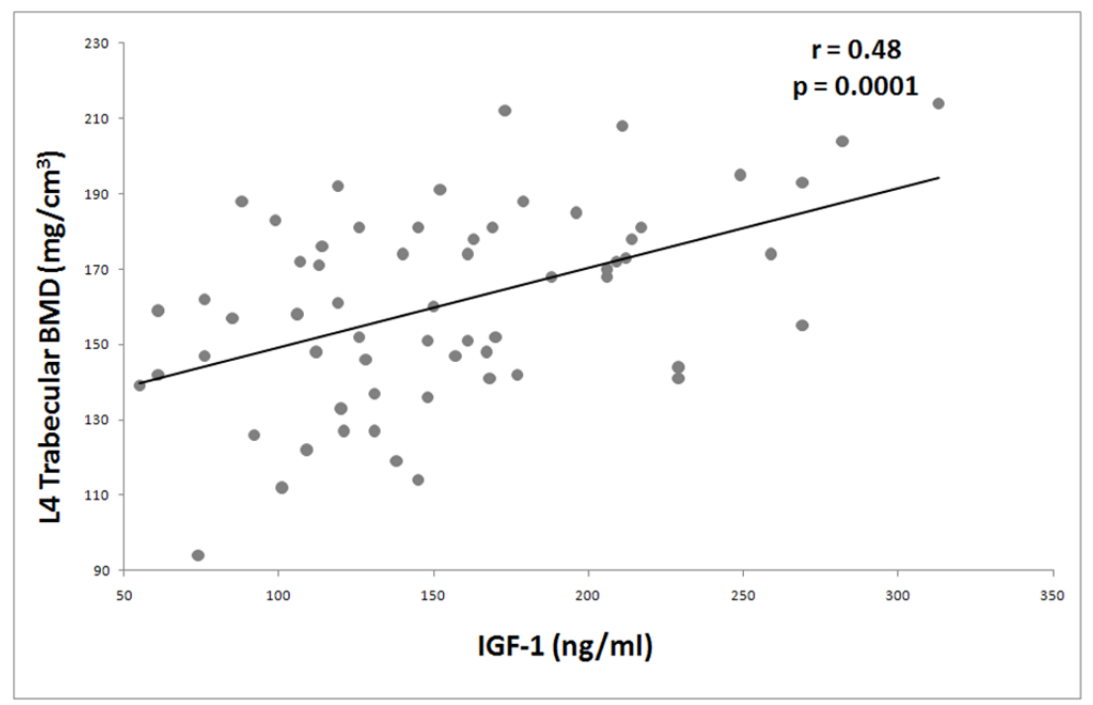

Figure 3.

Regression analysis of L4 trabecular BMD on insulin-type growth factor-1 (IGF-1). There is a positive correlation between bone mineral density and IGF-1. 


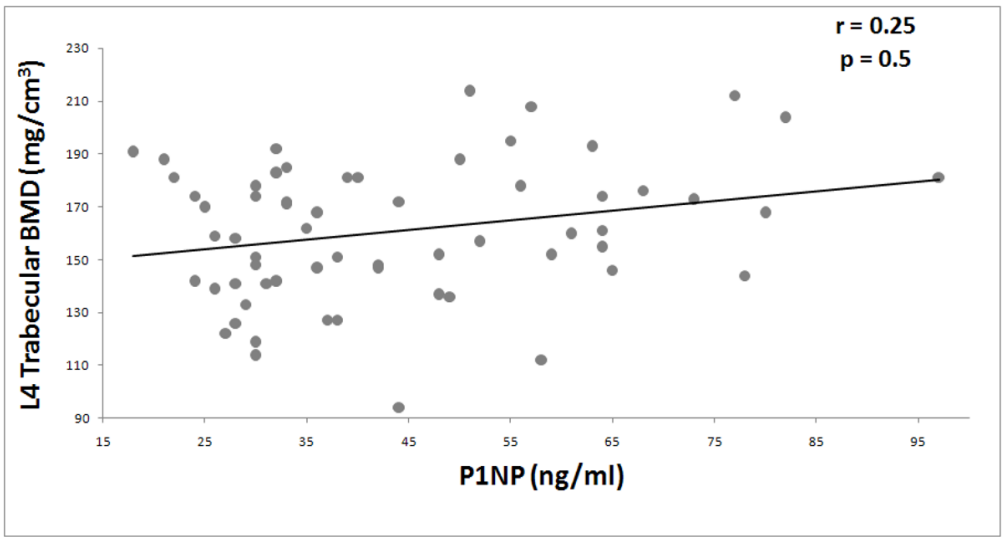

Figure 4.

Regression analysis of L4 trabecular BMD on $\mathrm{N}$-terminal propeptide of Type 1 procollagen (P1NP). There is a positive correlation between bone mineral density and P1NP. 


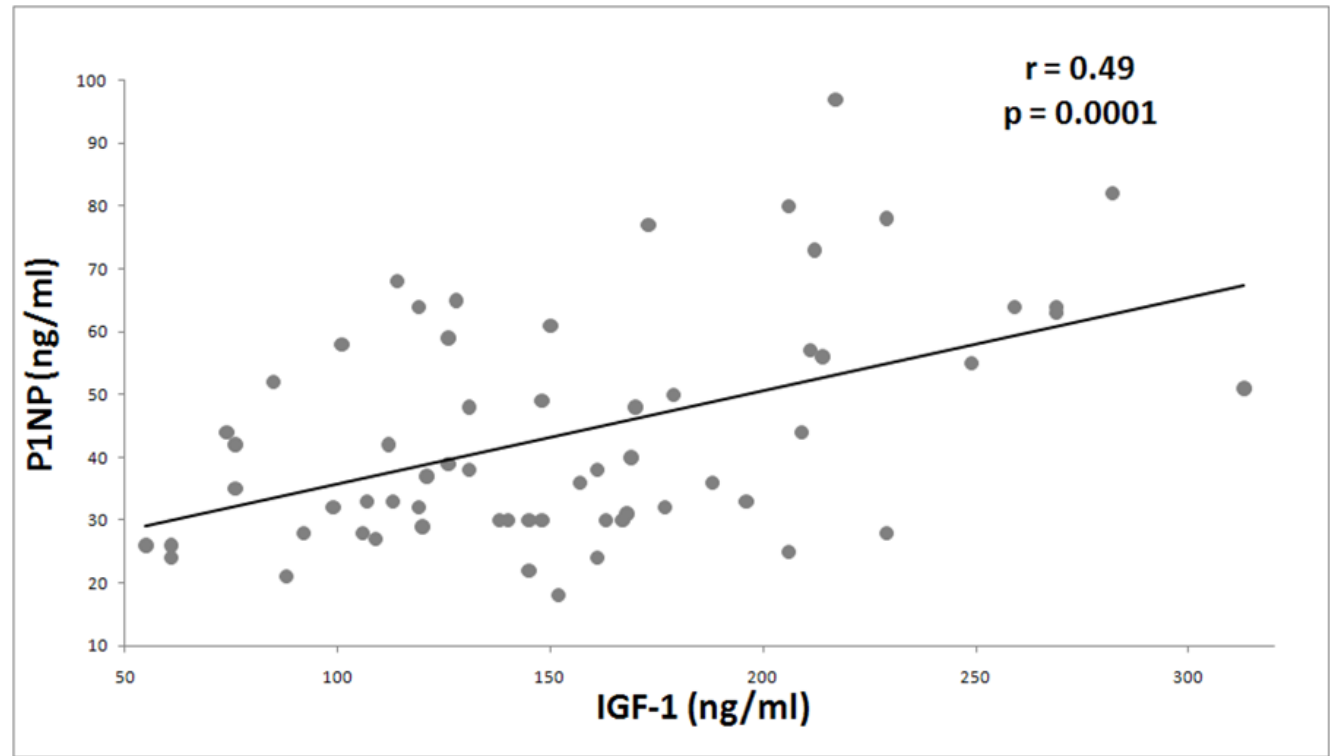

Figure 5.

Regression analysis of $\mathrm{N}$-terminal propeptide of Type 1 procollagen (P1NP) on insulin-like growth factor-1 (IGF-1). There is a positive correlation between P1NP and IGF-1. 


\section{Table 1}

Clinical characteristics of all study subjects (mean \pm SD)

\begin{tabular}{|c|c|}
\hline Variable & Subjects $(n=68)$ \\
\hline Age (years) & $35.9 \pm 6.7$ \\
\hline Weight (kg) & $97.0 \pm 13.5$ \\
\hline BMI $\left(\mathrm{kg} / \mathrm{m}^{2}\right)$ & $36.7 \pm 4.2$ \\
\hline IGF-1 (ng/ml) & $155.1 \pm 59.0$ \\
\hline 25 hydroxyvitamin D (25OHD) (ng/ml) & $24.1 \pm 15.2$ \\
\hline P1NP (ng/ml) & $43.9 \pm 18.0$ \\
\hline Total testosterone (ng/dl) & $34.3 \pm 21.0$ \\
\hline Free testosterone (ng/dl) & $0.54 \pm 0.43$ \\
\hline Total estradiol (pg/ml) & $115.1 \pm 94.0$ \\
\hline Free estradiol (pg/ml) & $74.6 \pm 59.4$ \\
\hline L4 trabecular BMD $\left(\mathrm{mg} / \mathrm{cm}^{3}\right)$ & $162.4 \pm 33.0$ \\
\hline SHBG (mmol/l) & $52.8 \pm 37.3$ \\
\hline CT: Abdominal TAT $\left(\mathrm{cm}^{2}\right)$ & $633.0 \pm 145.3$ \\
\hline CT: Abdominal SAT $\left(\mathrm{cm}^{2}\right)$ & $510.5 \pm 121.0$ \\
\hline CT: Abdominal VAT $\left(\mathrm{cm}^{2}\right)$ & $122.3 \pm 50.9$ \\
\hline CT: Thigh muscle CSA $\left(\mathrm{cm}^{2}\right)$ & $147.2 \pm 19.0$ \\
\hline CT: Thigh muscle density (HU) & $46.8 \pm 5.3$ \\
\hline CT: Thigh SAT $\left(\mathrm{cm}^{2}\right)$ & $204.6 \pm 57.4$ \\
\hline
\end{tabular}

P1NP: procollagen type 1 amino-terminal propeptide; SHBG: sex hormone binding globulin, BMD: bone mineral density, TAT: Total abdominal adipose tissue; SAT: Subcutaneous adipose tissue; VAT: Visceral adipose tissue, CSA: cross sectional area, HU: Hounsfield units 
Table 2

Associations of trabecular BMD with body composition and hormonal determinates of bone turnover

\begin{tabular}{lllll}
\hline & L4 Trabecular BMD & P1NP & \\
\hline & $\mathbf{r}$ & $\mathbf{p}$ & $\mathbf{r}$ & $\mathbf{p}$ \\
Age & -0.41 & 0.0006 & -0.38 & 0.002 \\
Weight & -0.20 & 0.1 & 0.17 & 0.2 \\
BMI & -0.20 & 0.1 & 0.16 & 0.2 \\
Abdominal TAT & -0.23 & 0.06 & 0.19 & 0.1 \\
Abdominal SAT & -0.21 & 0.1 & 0.31 & 0.02 \\
Abdominal VAT & -0.42 & 0.0005 & -0.21 & 0.09 \\
Thigh muscle CSA & 0.42 & 0.007 & 0.35 & 0.03 \\
Thigh muscle density & 0.36 & 0.02 & 0.31 & 0.05 \\
Thigh SAT & 0.26 & 0.1 & 0.11 & 0.5 \\
IGF-1 & 0.48 & 0.0001 & 0.49 & 0.0001 \\
25OHD & 0.04 & 0.7 & -0.15 & 0.2 \\
P1NP & 0.25 & 0.05 & & \\
\hline
\end{tabular}

